\title{
Diffusion and Adoption of IT Products and Processes in a Danish Bank
}

\author{
Jan Pries-Heje ${ }^{1}$ and Susanne Tryde ${ }^{2}$ \\ 'Department of Computer Information Systems, Georgia State University, 35 Broad Street, \\ Atlanta, Georgia 30302, USA \\ Tel. $+404651-3822$ \\ Fax: +404 651-3842 \\ Email: jpries@cis.gsu.edu \\ ${ }^{2}$ Danske Bank, Holmens Kanal 2-12, 1092 København K., Denmark
}

Key words: Diffusion and adoption of IT, Implementation of IT, Organizational learning.

\begin{abstract}
This paper is about a successful diffusion and adoption effort launched in 1998 and continued for more than two years. The effort took place in the IT organization of a major Danish bank. As part of the effort a diffusion framework was developed to be used by IT projects. This framework was used in more than 30 projects to improve the changes of successful diffusion of the products being developed in the projects. And it worked. Interview data from May and June 2000, interviewing projects up to a year after they used the framework, shows a high level of satisfaction and successful product diffusion.
\end{abstract}

\section{INTRODUCTION}

Many resources are spent in IT companies developing IT products and processes that are never used as planned. There may be many reasons for this. Perhaps, management lost interest in the project. Perhaps, the project developing the new product failed to establish contact with future users and their real needs. Or perhaps, the project forgot to take advice from stakeholders in the project, who consequently blocked diffusion and adoption. 
Problems connected with diffusion or implementation of software are not unknown. Rogers' (1995, pp. 5-6) book "Diffusion of Innovations" defines diffusion in the following way:

"Diffusion is the process by which an innovation is communicated through certain channels over time among the members of a social system ... diffusion is a special type of communication, in which the messages are about a new idea. The newness of the idea in the message content gives diffusion its special character. The newness means that some degree of uncertainty is involved in diffusion. Uncertainty is the degree to which a number of alternatives are perceived ... Diffusion is a kind of social change, defined as the process by which alteration occurs in the structure and function of a social system."

The central elements in diffusion are:

1. An innovation.

2. Communication through certain channels over time.

3. The diffusion and the change it leads to in the target group.

4. The uncertainty related to the many alternative ways in which the idea may be employed, the many ways in which communication may take place and the many ways in which changes may occur.

An innovation may be a product, a service or an idea that somebody perceives as new (Kotler, 1998, p. 439). Often, innovation is used as a term for a consumer's view on newly introduced products (see e.g. Mowen, 1995 or Rogers, 1979). According to Rogers, it is not important whether an innovation is new from an objective point of view as long as somebody perceives it as new.

The element of communication requires that developers and users arrive at a common understanding by creating and sharing information. Rogers (1995, p. 17) distinguishes between two kinds of communication channels; mass media and personal channels. By mass media, we understand TV, radio, newspapers, newsletters, etc., while personal communication may involve face-to-face messages or meetings. When it comes to convincing a target group, personal communication channels are generally most effective.

In connection with the communication and time dimensions, there is a range of phase models. Cooper \& Zmud (1990) and Kwon \& Zmud (1987) present the most prevalent phase model describing the diffusion of ITproducts. It operates with six phases called: (1) Initiation. (2) Decision. (3) Adaptation. (4) Accept and adoption. (5) Routine procedures. (6) Infusion/penetration.

Related to the phase model a more normative model describing implementation strategies to be used in different situations has been developed by Ken Eason (1988). And following the same line of thought Targama (1978) and Bendix \& Andersen (1995) have developed 
Scandinavian models that can be used to choose an implementation strategy based on questions such as: Was the project idea initiated from the target group? To what extent is the successful implementation dependent on target group acceptance? And are the consequences for the target group primarily seen as positive or negative?

The target group involves a social system that in itself sets certain limits to how diffusion can take place. The social system consists of related persons, groups and departments, and both formal and informal structures have an effect. However, it is characteristic that people that is adopting an innovation needs to make the adoption decision themselves. Therefore, many researchers have focused on the individual's resistance towards change (see e.g. Levine, 1997) or on the chaos perceived by the individual when a foreign element - innovation - enters his/her world (Weinberg, 1997).

All in all, there are a number of descriptive theories and models dealing with diffusion. However, to bring them into practical use is not in an easy task. For specific IT development tools Mathiassen and Sørensen (1997) have developed a framework. But for more general use very little is reported in the IT literature.

\section{DANSKE BANK AND DANSKE DATA}

Danske Bank is one of the largest banks in Scandinavia with more than 20.000 employees. Within Danske Bank there is a large IT department called Danske Data. From 1996 to 2000 the IT department worked as an independent software house. But for strategic reasons Danske Data was made an internal IT department again in 2000. In this paper we will use the term Danske Data to refer to the IT organization in the bank and Danske Bank to refer to the remainder of the organization.

Danske Data is physically situated at four different locations in Denmark, namely in Ejby west of Copenhagen, in Lyngby north of Copenhagen, in Brabrand close to Aarhus in Jutland, and in Nykøbing Falster $150 \mathrm{~km}$ south of Copenhagen. Approximately 900 employees are working in Danske Data.

The main products produced by Danske Data are applications for banking and insurance. Primarily applications are meant to run on a mainframe, but some applications are for Internet banking, client/server-environments, and PCs. Danske Data mainframe systems are up and running 24 hours a day, and every day 9 million transactions are carried out from 11.000 workstations. The developers within Danske Data typically have IT educations, at bachelor level, or come from a background in banking. Recently more and more employees with a master's degree have been hired. 
Danske Data was assessed in May 1997. From this assessment it became clear that many products and processes developed by Danske Data were not diffused and adopted as intended. In the assessment report it was said: "Why are so many procedures well described but not used?" (Delta, 1997). The assessment report suggested that the company should make a further analysis of diffusion and adoption, which was subsequently done. A task force of three people including the authors of this paper was set up.

\section{RESEARCH METHOD}

To cope with the problem identified - lack of diffusion and adoption - we have used action research. Bob Galliers (1992) describes action research as an approach that allows us to create new theoretical knowledge in addition to something that has practical value for the organization under research. The approach that we adopted in our action research is based on the five phases recommended by Susman \& Evered (1995): (1) Specification of infrastructure in project. (2) Diagnosis of problem. (3) Planning of actions. (4) Implementing actions. (5) Evaluation of results. Repeat phase (2) to (5), if necessary.

The infrastructure of the project was set up in the fall of 1997. Insightful people from all parts of the organization being it project managers, line managers or people from the methodology department were asked and agreed to be part of a task force.

In two workshops in January and February 1998 the task force diagnosed the diffusion and adoption problem. In the first workshop the cause of the inadequate diffusion and adoption was narrowed down to a number of issues. In the second workshop, one month later, identified a number of solutions to the problems, and in April 1998 the company implemented organizational changes solving many of the structural problems. The remaining problem was to ensure diffusion and adoption of products and processes from IT projects. How does an individual project ensure that its new product will be used as expected when it has been completed? To answer this specific problem the infrastructure of the project was changed from a 12-people task force to a small group of three, each working half of their available time.

While studying the organization's successes and failures in the first workshop we quickly realized that attempts to ensure diffusion by adding some additional activities at the end of the project often fail. It is necessary to start such attempts so early in the project that they will have an effect on the product itself. Therefore, we decided to make a framework to be used in a one-day workshop for projects focusing on diffusion and adoption right 
after the requirements to a given product had been defined. At that specific point of time, the project group knows how the product is going to appear although no specific solutions have yet been prepared.

A major reason for choosing a one-day workshop was that one of the few successful diffusion efforts we identified in the organization was a so-called analysis workshop used to bring customers and developers together and agree on scope and requirements. Therefore projects within Danske Data were familiar with the workshop concept so when we planned our actions we decided to take advantage of this mechanism already in place.

Concurrently with studying cases from our own organization, we read the studies of others on diffusion and adoption of IT. The literature did not give us a holistic and action-oriented solution to diffusion and adoption, but different authors who had analyzed various elements of the issue (as mentioned in the introduction) did inspire us.

Based on the case study and details from the various articles, we developed our first version of our framework to be used in a workshop around New Year 1998-99. Our first test took place in three projects in February 1999. The test resulted in a number of adjustments. The same thing happened after the second iteration in two workshops. It was not until the third iteration that the framework and the workshop found a form that was acceptable for internal projects. A fourth and fifth iteration was carried out in the fall of 1999 and the spring of 2000 to adapt the framework to external projects - meaning projects involving customers from the bank or outside the Bank.

When using action research for the kind of study described here there is a number of things to be aware of. First of all you need to strive for rigorous and disciplined action research (Baskerville \& Wood-Harper 1996). To ensure that all our data collection was done during and immediately after the workshops. We video-taped every workshop and used the tapes to make sure that we had captured every important piece of information. And we wrote a summary for each workshop that were send to the participants so they could acknowledge that we had captured all decisions and discussions correctly.

Furthermore when we adjusted our framework - as described above - we always tried things twice and looked for at least two consistent observations of non-satisfactory workshop results before we adjusted the framework. The interpretation of results was done in a group of two or three with at least one researcher and one practitioner taking part. The decision to change or adjust the framework was agreed by the whole group every time. Thus by doing the adjustments in such a rigorous way we hoped to avoid the danger of making to many "in-flight changes" that complicated or compromised our framework instead of improving it. 
For evaluation we used a questionnaire that all workshop participants filled out after the workshop. This gave us valuable information that we used to re-design the framework, which we have called the first to sixth iteration above. However, this kind of evaluation did not give us insight into the longitudinal consequences. Was the framework really working? Did the products really diffuse better? These were some of the questions that we were asking.

To answer the questions we interviewed 12 participants from six projects that had completed a workshop up to year earlier and that in most cases were over their implementation. For the interviews we used a structured interview guide, we transcribed the interview, and we coded and analyzed the interviews. The interviews took place in May and June 2000, and after careful analysis we closed the project concluding that we had successfully contributed to solving the problem of lack of adoption and diffusion.

\section{THE FRAMEWORK}

The framework consisting of a one-day workshop is focusing both on the product that is to be diffused, and on the diffusion process in itself.

The workshop is divided into three phases called analysis, design, and planning, each covering two stages. 


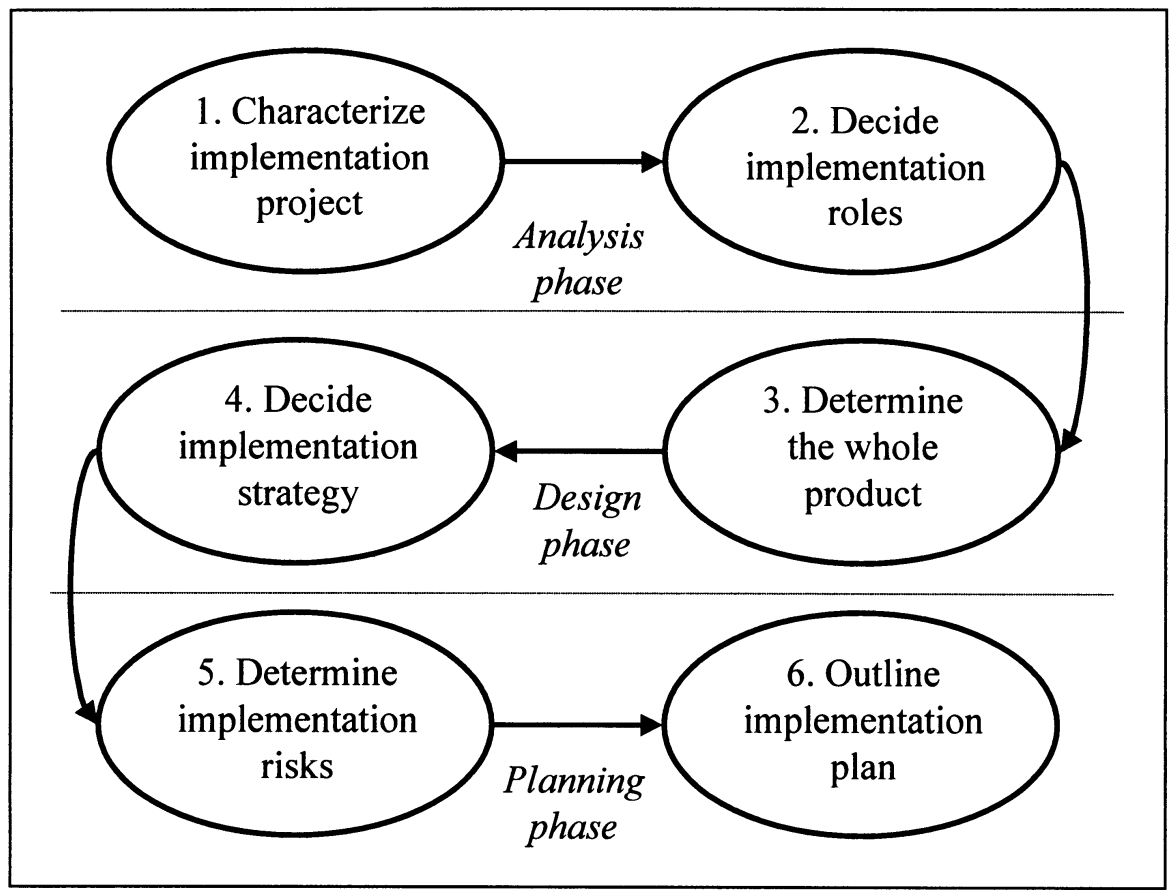

Figure 1. Overview of the six stages and three phases in the workshop.

The workshop starts with an introduction so the participants know what to expect at the end of the day. At the same time the workshop facilitators learn about the project and the product.

In the analysis phase the purpose is to get a common understanding of the size and effort the implementation process will require.

The design phase ensures that the project group focus on how the product has to be "packaged" to be seen as a whole product by the target user group. Furthermore the best implementation strategy is selected in the design phase.

In the planning phase, all the threads are gathered from the previous operations. An outline of the implementation plan is prepared comprising all the activities identified through the first three phases.

\subsection{Analysis Phase}

The analysis consists of two stages. First, we focus on a range of questions in order to characterize the project. The purpose is to create a common understanding of the product that is going to be the outcome of the project. Second, we focus on who is playing which roles in the project.

The first stage of the analysis is titled "Characterize implementation project" and includes four questions. Inspiration to the first part of the 
analysis comes from Mathiassen and Sørensen (1997). Table 1 shows the questions in the left column and typical replies in the right column.

Table 1. Questions used to characterize project

\begin{tabular}{|c|c|}
\hline Questions & Typical replies \\
\hline $\begin{array}{l}\text { 1. Why should the product be } \\
\text { diffused? }\end{array}$ & $\begin{array}{ll}\text { - } & \text { There is a need for ... } \\
\text { - } & \text { Company strategy requires ... } \\
\text { - } & \text { We must have this technology ... }\end{array}$ \\
\hline $\begin{array}{l}\text { 2. What is the purpose of the } \\
\text { product? }\end{array}$ & $\begin{array}{ll}\text { - } & \text { To support administration } \\
\text { - } & \text { To support project management } \\
\text { - } & \text { To support IT development } \\
\text { - } & \text { To support IT operations }\end{array}$ \\
\hline $\begin{array}{l}\text { 3. Who must change their way of } \\
\text { working when the product has been } \\
\text { implemented? }\end{array}$ & $\begin{array}{l}\text { - Software developers (host developers, } \\
\text { client/server developers) } \\
\text { - Experts in specific fields (database, } \\
\text { economics, personnel) } \\
\text { - Managers (project managers, line managers, } \\
\text { senior managers) }\end{array}$ \\
\hline $\begin{array}{l}\text { 4. Where and in which sequences } \\
\text { will the product be used? }\end{array}$ & 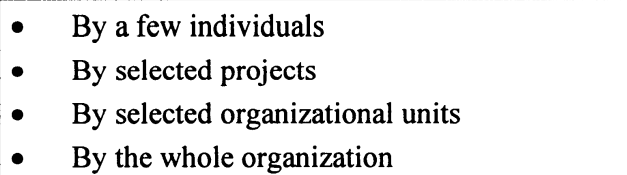 \\
\hline
\end{tabular}

The second stage of the analysis is titled "Determining who should play which parts" In this connection, we apply a role model inspired by Checkland \& Scholes (1990) and Bendix \& Andersen (1995).

The main idea of the role model is that five roles must be filled if implementation is going to succeed. If one of the roles has not been filled, implementation will fail. The five roles are:

1. The target group are the persons who are going to use the product

2. The owner/sponsor is responsible for initiating the implementation and scoping the direction. Towards the end of the implementation the owner /sponsor also is responsible for demanding the results coming out of the implementation.

3. The manager of implementation is the person doing the actual implementation work. Often this role is named the project manager.

4. The champion/ambassador are the persons who actually makes the people from the target group take the innovation into use. 
5. "Other secondary stakeholders" consists of all other interested parties not taking any of the four primary roles.

In figure 2 the roles are placed around a big arrow that symbolizes implementation from the first tentative idea about a product at the extreme left to the product hits the target group at the right where it is diffused and put into use. Based on a detailed description of the roles, the project group has to fill the roles in relation to their specific product.

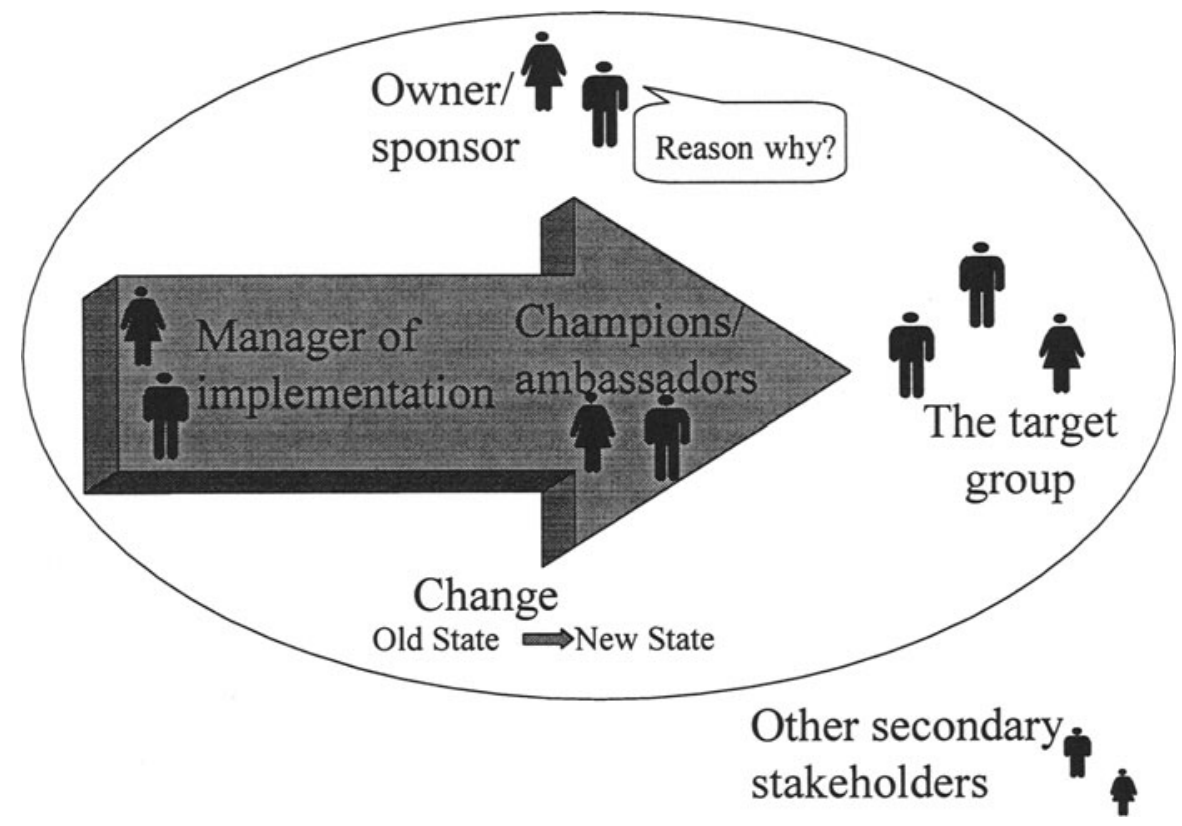

Figure 2. The role model indicating central roles.

\subsection{Design Phase}

The design phase consists of two stages. First, we try to define "the whole product". Second, we examine how to organize the implementation of the product. The purpose is partly to clarify what kind of product we have to make in order to improve the chances of success in implementation. And partly to create a framework for an implementation plan that can be used in the subsequent phase. The idea behind "the whole product" is that the user of a new product normally expects to get more than a mere technical solution. Therefore, we are working with three product levels (Moore 1991):

1. The core product

2. The whole product 
3. The expanded product

The core product is the developers' idea of what they have to prepare in order to give the customers what they promised. I.e. a developer who is going to develop a HomeBanking system may regard the computer program as the core product.

The whole product is the customer's idea of what he/she will get - i.e. the core product including related supplementary products to ensure that the product is easy to use. I.e. a customer who is buying a HomeBanking system will expect to get the disks with the program in addition to a quick guide, hot-line telephone support, and a tutorial.

The expanded product is not relevant until the whole product has been put into operation and the customer or the developer suggests supplementing the existing product with an additional service. For example, the customer might wish that the HomeBanking system also included a tax calculation feature.

In the workshop, we start by having a brainstorm indicating the ideas that the project group has about the "whole" product. Then, the project group is guided through a range of questions characterizing the target group and the core product. This procedure leads to a range of supplementary products that can support implementation of the core product. The end result is a clear definition of the core product and which supplementary products must be developed in order to meet the target group's expectations. The questions posed fall in three groups:

1. First we address the complexity and size of the project. The larger the project is, the less possible it becomes that the people implementing the project also can fulfill the role as ambassador or champion towards the target group. I.e. a project group of 8 people can never reach a target group of 8000 working in branches of the bank within a reasonable time frame. Complexity describes whether the product being developed has many interfaces to other systems, and whether it solves many problems for the target group.

2. Second we examine familiarity of the product that is to be developed in the project. How many functions are new and how many were in a former system? Will the organization or workflows be changed? And do the target group have experience with the technology applied.

3. Third we ask whether the product is aimed at a homogenous or a mixed target group?

For each of the eight combinations of the three dimensions we have identified a number of measures and actions that may be included in the implementation plan. When we relate the specific project to the three dimensions, we get a number of specific measures and actions that the project group can discuss whether to use in the concrete implementation. 
The second stage of the design phase deals with how to organize implementation. For this purpose we have used a theory on implementation strategies developed by Ken Eason (1988). The theory comprises five different strategies from the most revolutionary strategy - where the users abandon their old system one day and adopt the new system on the following day - to the most evolutionary approach where the users over a period of months or years, little by little, start using more and more of the new system. Eason's five strategies are called:

1. Big Bang

2. Parallel application

3. Phased introduction

4. Experimental diffusion

5. User-based experiment

The 'Big Bang' strategy implies that all users shift to the new system all at once. 'Parallel application' means that the old system continues to function in a certain period after the new system has been launched. 'Phased introduction' implies that the system is divided into phases in such a way that the entire target group gradually start applying more and more of the system. Or it may imply that the whole system is put into operation by part of the target group and subsequently the rest of the group will follow step by step, part by part. In 'Experimental diffusion', the system is tested by part of the target group. After a period of time, the experiences are compared with the test results, and it is decided to which extent the experiment should be diffused to others or made permanent. In the 'User-based experiment', the users themselves test the system in order to determine what they can achieve by using the system.

The relationship between the five strategies seen in relation to user participation and revolution-evolution is shown in figure 3. 
Revolution

- Big Bang

- Parallel application

- Phased introduction

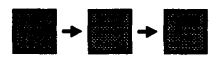

- Experimental diffusion

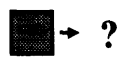

- User-based experiment

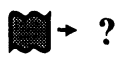

User Participation

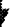

Evolution

Figure 3. The five implementation strategies (from Eason 1987)

The five implementation strategies are not mutually exclusive, but can be applied in combination.

In the workshop we analyze each of the five implementation strategies focusing on advantages and disadvantages. We emphasize that the demand for user participation in the development process is increasing from low participation in the 'Big Bang' approach to high participation in the 'Userbased experiment'. In terms of implementing the approaches, there is a movement from a very controlled approach in 'Big Bang' to a very experimental approach in 'User-based experiment'.

However, 'Experimental diffusion' and 'User-based experiment' are not real options as it has already been decided to implement the system/product. The purpose of the workshop is to choose the most suitable way of implementation.

An outline of the implementation plan is made with phases and benchmarks depending on which strategy is chosen. For example, the 'Big Bang' approach has only one phase (before implementation) and one benchmark (implementation completed) as everything must be prepared for the big moment, the 'Big Bang'.

In the end, the design phase will give the project group a clear idea of how implementation should be carried out in general. 


\subsection{Planning Phase}

Similar to the two previous phases, this phase also has two stages: a risk analysis and an implementation planning stage. In the first stage of the planning phase, we perform a risk analysis in order to ensure that we haven't overlooked any potential problems. Risk management deals with identifying and reacting to potential problems in time. Risk management often leads to proactive activities. In our risk analysis we focus on the following six issues:

1. Identify risks. Here we use a standard list of the ten highest risks in the organization based on the organization's own experience.

2. Assess the probability for every risk on a scale from one to five.

3. Assess the consequence of every risk on a scale from one to five.

4. Make a list of priorities by multiplying probability with consequence.

5. Find activities - proactive or supportive - that relate to the three most important risks.

6. List the chosen activities as items that should be included in the implementation plan.

The second stage is to outline an implementation plan. During the workshop all activities mentioned by the project group are being written down on small notes. These notes - which are appropriate implementation activities - are now placed on a blackboard or a table where the benchmarks and the intermediate states are outlined. It may look as indicated in figure 4.

The last stage of the workshop provides the project group with a good outline of the implementation plan. It may be applied directly in connection with estimating the implementation phase and as input to the project plan and the final implementation plan of the project.

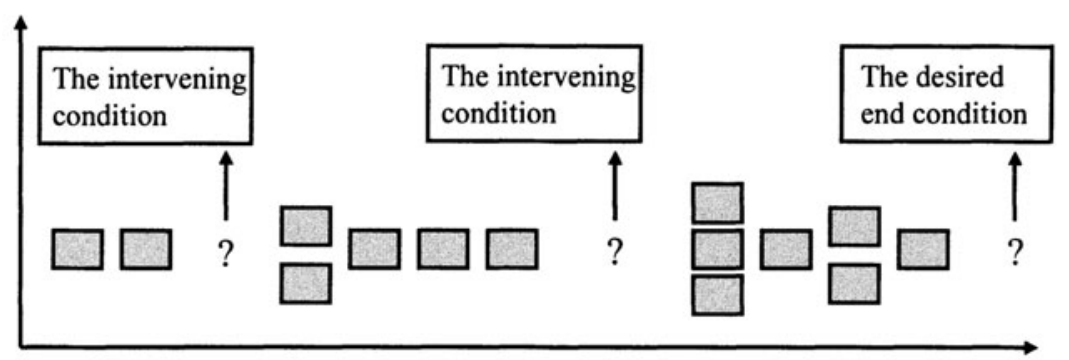

Time

Figure 4. The implementation plan made with yellow stickers on a whiteboard

\section{LESSONS LEARNED}

While developing the approach using action research we have learned a number of lessons as explained below. 


\subsection{First Lesson: Use detailed description of the target area}

The first stage of the approach has changed a number of times. We started out with a few who-what-where questions, but soon realized that we needed more knowledge about the project in question to be able to effectively facilitate the use of the approach. Therefore we now use the questions shown earlier in table 1. Furthermore we also ask what motivates or motivated the owner or sponsor to initiate the project, and we discuss the desired result of the project at length. All in all it typically takes 60-80 minutes to describe the target area in enough detail so we - as facilitators coming from outside the project - are able to identify ourselves with the project group and its context.

\subsection{Second Lesson: Detailed stakeholder analysis is not necessary - the role model is better}

When we first developed the approach we used a traditional stakeholder analysis to identify all stakeholders. In one case we identified more than 30 stakeholders. Unfortunately we could not use all that information for anything meaningful. Therefore we now use the role model (figure 3) as the only stakeholder analysis. We believe the role model covers the major roles in any organizational implementation - at least the ones we have met. And we have often found that one or even two of the roles were not filled with "actors" from the organization in the concrete project. So the use of the role model often leads to the identification of a major potential problem; the lack ofan important role being played in the implementation enacting.

\subsection{Third Lesson: You can easily focus too much on implementation strategy}

Literature on diffusion and adoption of IT often considers implementation strategy at length. At the beginning of our action research we had the same strong focus on strategy. Based on Targama (1978) and Bendix \& Andersen (1995) we went through a tedious process on determining whether to use an expert implementation strategy, a line management implementation strategy, a project change implementation strategy, or a process change implementation strategy. The decision on the strategy then led to a number of general recommendations.

Example: IF the dependency of active acceptance from the target group is low AND the consequences for the people that are influenced by the change 
introduced are mainly negative, THEN use an expert based strategy, and be aware of the huge resistance to change this strategy may create. However after having tried out this way of looking at implementation strategy a number of times we realized that we were wasting our time. The advice that came out was simply too general and not useful to the projects. Instead we found Eason's model (figure 3) that is now included in the approach. We use Eason's model to select not a strategy but an approach. The gain from using Eason is that the project gets an idea of possible phases in the organizational implementation. Eason's model has worked well in projects that have used the approach very early, which means just after the scooping of the project. On the other hand we have also found that projects that are well into the analysis or design of the technical solution have less to gain from the use of the model. Our recommendation is therefore to use this stage of the approach only for projects early in their life cycle.

\subsection{Fourth Lesson: Determination of the whole product is essential}

In the first version of our approach we had three dimensions or question types that we used to determine the whole product. However, we found that two of dimensions - familiarity of application and familiarity with technology - were overlapping, at least in the minds of the participants. We also found that size was very difficult to determine at an early stage of a project. Therefore we ended up with the three questions we now have.

Furthermore we have found that it is necessary to explain in detail what the whole product means. Often we have found that the more technically oriented people in software projects have needed a lot of explanation before they understand that a technical solution is not enough. In the concrete we have used the five adopter categories (Rogers 1995), from the "innovators" to the "laggards", and the gap - or "chasm" as Moore $(1995,1998)$ calls it to explain why different parts of the target group in many projects needs more than just a core product.

\subsection{Fifth Lesson: Implementation risks should be discussed before the planning}

The content of the implementation phase in our approach has not changed since the first draft. But we have switched the two stages, discussing risks, and outlining the implementation plan. First we started out with the planning. Then we tried to identify and analyze risks. But we found that the participants in the workshops were quite unwilling to discuss risks 
after having outlined a plan. Instead we tried doing the risk analysis before the planning, and it worked well. Thus we have learned that the openness and reflection needed to look into potential problems - risks - are better achieved before planning than after.

\section{DISCUSSION AND CONCLUSION}

The approach for organizational implementation that we have developed is to our knowledge quite unique. The uniqueness, however, does not lie in the six stages one by one but in the combination and cohesion of the stages and phases as we have described in this paper.

One can of course use each of the stages of the approach for different purposes. But if you are to use the whole approach we have found that a oneday 7-hour workshop with 6-8 participants representing important stakeholders in a software process improvement project is very fruitful. The evaluations we have gotten from approximately 30 projects have been that the time spent in a workshop using the approach was well spent - the benefits gained were much greater than the investment in time needed. They also have told us quite unanimously that they never would have been able to come up with such a detailed and targeted improvement plan as the one they ended up with at the end of the day.

To validate our approach we have also interviewed 12 workshop participants from six workshops including users from the target group of one project. The interviews took place 6-12 months after the workshop at a time where the implementation planned at the workshop had been carried out. Each interview lasted between 30 minutes and 1 hour. In the interviews we used the summary from the workshop to go over each stage of the workshop trying to evaluate the details, and we asked about the workshop as a whole trying to evaluate the workshop in general. In figure 5 you find citations from the workshop participants we interviewed 6-12 months after the workshop. 
"I am pretty sure the workshop made a difference ... we have done things in this project that
we would never have done without."
"The organizational implementation has succeeded beyond our expectations. We have had
very few significant problems."
"If I should criticize something I believe we used a lot of time on a plan we weren't
committed to use."
"Especially the activities in the proposed plan have been helpful."
"We came to focus on a number of activities that we hadn't thought of before the workshop."
"We got the summary from the workshop and it was strongly recommended that we should
identify an owner/sponsor. But we never did."

Figure 5. Citations from evaluation interviews.

Our preliminary interpretation of the interview results is that in 5 out 6 projects the participants actually had carried out the activities included in the implementation plan. In general they were quite satisfied with the results. And they still evaluated the workshop as a very valuable and influential experience. But it is difficult to say anything definite before all implementations have been completed in well over a year (from fall 2000). The fact that many projects of their own accord have asked to participate in an implementation workshop also indicates that the concept works. Finally in October 1999 another maturity assessment - like the one in May 1997 that gave birth to our study - was carried out by independent assessors from outside Danske Data (Delta, 1999). This assessment found that diffusion and adoption was not one of the top five problems in the organization any more and emphasized the successful diffusion and adoption of the IT processes from three projects with whom we have had workshops.

In conclusion, we find that the framework described here appears to be a good bid for a solution to the problem with diffusion and adoption that many companies are facing. Furthermore a project manager can use our approach, either coming from the development side or from the user side, or it can be used by another kind of group responsible for software process improvement. The use of the approach can either rigorously follow the six stages in the recommended order (phases), or any of the six stages can be used separately 


\section{REFERENCES}

Baskerville, R. and Wood-Harper, T. (1996) A critical perspective on action research as a method for IS research, Journal of Information Technology, Vol. 11, No. 4, pp. 235-246.

Bendix, Jan \& Ole Steen Andersen (1995). Forandringsledelse - kommunikation, adfard og samarbejde. Børsens Forlag.

Checkland, Peter \& Jim Scholes (1990). Soft Systems Methodology in Action. John Wiley \& Sons Ltd., West Sussex - England.

Cooper, R. \& R. Zmud (1990). Information Technology Implementation Research: A Technological Diffusion Approach. Management Science, 36, 2: 123-139.

Delta (1997). Danish Light, Electronics and Acoustics (1997). BOOTSTRAP Assessment Report. Danske Data A/S. DELTA document no. 500069D. Issued 01.07.97.

Delta (1999). Danish Light, Electronics and Acoustics (1999). BOOTSTRAP Assessment Report. Danske Data A/S. DELTA document no. 500069D - F. Issued 01.11.99.

Eason, Ken (1988). Information Technology and Organisational Change.Taylor \& Francis.

Galliers, R. (1992). Choosing Information Systems Research Approaches. In: Galliers, R. (Ed.). Information Systems research: Issues, Methods and Practical Guidelines. Blackwell scientific Publications. Oxford, England.

Kotler, P. (1988) Marketing Management: Analysis, Planning, Implementqtion, and Control 6th Edition. Prentice-Hall, Englewood Cliffs, N.J.

Kwon, T. and Zmud, R. (1987). Unifying the fragmented models of information systems implementation, in Boland, R. and Hirschheim, R. (eds.) Critical Issues in Information Systems Research. Wiley, New York. 227-251.

Levine, Linda (1997). An ecology of resistance. I: McMaster, T., E. Mumford, E. Burton Swanson, B. Warboys \& D. Wastell (Eds.). Facilitating technology Transfer through Partnership: Learning from Practice and Research. Chapman \& Hall. Side 163-174.

Mathiassen, Lars \& Carsten Sørensen (1997). A guide to manage new software engineering tools. In: McMaster, T., E. Mumford, E. Burton Swanson, B. Warboys \& D. Wastell (Eds.). Facilitating technology Transfer through Partnership: Learning from Practice and Research. Chapman \& Hall. Side 257-272.

Moore, Geoffrey (1995). Inside the Tornado. Harper Business.

Moore, Geoffrey (1998, 1991). Crossing the Chasm: Marketing and Selling technology products to Mainstream Customers. Capstone.

Mowen, J. (1995) Consumer Behaviour 4th Edition. Prentice-Hall, Englewood Cliffs, N.J.

Rogers, Everett. (1979). New product adoption and diffusion, Journal of Consumer Research (March), 290-301, reprinted in Ben Enis and Keith Cox (eds) Marketing Classics: A Selection of Influential Articles 5th Edition. Allyn and Bacon, Boston, Mass, 1985, 164179.

Rogers, Everett M. (1995). Diffusion of Innovations. $4^{\text {th }}$ Edition. Free Press, New York.

Susman, G. and Evered, R. (1978). An assessment of the scientific merits of action research. Administrative Science Quarterly 23 (4): 582-603.

Targama, Axel (1978). Former for administrativt udviklingsarbejde. ISBN: 917246017.

Weinberg, Gerald M. (1997). Quality Software Management, Volume 4: Anticipating Change. Dorset House, New York. 